\title{
Exosomal LncRNA-NEAT1 derived from MIF-treated mesenchymal stem cells protected against doxorubicin-induced cardiac senescence through sponging miR-221-3p
}

\author{
Lei Zhuang ${ }^{1 \dagger}$, Wenzheng $\mathrm{Xia}^{2,3+}$, Didi Chen ${ }^{4}$, Yijia Ye ${ }^{4}$, Tingting $\mathrm{Hu}^{4}$, Shiting $\mathrm{Li}^{3^{*+}}$ and Meng Hou ${ }^{4 * \dagger}$
}

\begin{abstract}
Background: The chemotherapy drug doxorubicin (Dox) is widely used for treating a variety of cancers. However, its high cardiotoxicity hampered its clinical use. Exosomes derived from stem cells showed a therapeutic effect against Dox-induced cardiomyopathy (DIC). Previous studies reported that exosomes derived from mesenchymal stem cells (MSCs) pretreated with macrophage migration inhibitory factor (MIF) (exosome ${ }^{\mathrm{MIF}}$ ) showed a cardioprotective effect through modulating long noncoding RNAs/microRNAs (IncRNAs/miRs). This study aimed to investigate the role of exosome $\mathrm{MIF}^{\mathrm{II}}$ in the treatment of DIC.
\end{abstract}

Results: Exosomes were isolated from control MSCs (exosome) and MIF-pretreated MSCs (exosome ${ }^{\mathrm{MIF}}$ ). Regulatory IncRNAs activated by MIF pretreatment were explored using genomics approaches. Fluorescence-labeled exosomes were tracked in vitro by fluorescence imaging. In vivo and in vitro, miR-221-3p mimic transfection enforced miR-221-3p overexpression, and senescence-associated $\beta$-galactosidase assay was applied to test cellular senescence. Exosomal delivering LncRNA-NEAT1 induced therapeutic effect in vivo was confirmed by echocardiography. It demonstrated that exosomes ${ }^{\mathrm{MIF}}$ recovered the cardiac function and exerted the anti-senescent effect through LncRNA-NEAT1 transfer against Dox. TargetScan and luciferase assay showed that miR-221-3p targeted the Sirt2 3'-untranslated region. Silencing LncRNA-NEAT1 in MSCs, miR-221-3p overexpression or Sirt2 silencing in cardiomyocytes decreased the exosome ${ }^{\mathrm{MIF}}$-induced anti-senescent effect against Dox.

Conclusions: The results indicated exosome ${ }^{\mathrm{MIF}}$ serving as a promising anti-senescent effector against Dox-induced cardiotoxicity through LncRNA-NEAT1 transfer, thus inhibiting miR-221-3p and leading to Sirt2 activation. The study proposed that exosome ${ }^{\mathrm{MIF}}$ might have the potential to serve as a cardioprotective therapeutic agent during cancer chemotherapy.

Keywords: Mesenchymal stem cells, Exosome, Macrophage migration inhibitory factor (MIF), Doxorubicin-induced cardiomyopathy, LncRNA-NEAT1/miR-221-3p/Sirt2 signaling pathway

*Correspondence: lishiting@xinhuamed.com.cn; 244517813@qq.com

'Lei Zhuang and Wenzheng Xia contributed equally to this work

†Shiting Li and Meng Hou contributed equally to this work

${ }^{3}$ Department of Neurosurgery, Xinhua Hospital Affiliated to Shanghai

Jiaotong University School of Medicine, Shanghai 200092, China

${ }^{4}$ Department of Radiation Oncology, First Affiliated Hospital, Wenzhou

Medical University, No. 2 Fuxue Lane, Wenzhou 325000, People's Republic of China

Full list of author information is available at the end of the article

\begin{abstract}
Background
Advances in cancer chemotherapy have led to a remarkable decrease in mortality rates and, consequently, a rapid increase in the number of cancer survivors [1]. Many of these cancer survivors suffer from chemotherapy-related cardiac complications later in life. Cardiovascular adverse effects have become the second leading cause of death
\end{abstract}

c) The Author(s) 2020. This article is licensed under a Creative Commons Attribution 4.0 International License, which permits use, sharing, adaptation, distribution and reproduction in any medium or format, as long as you give appropriate credit to the original author(s) and the source, provide a link to the Creative Commons licence, and indicate if changes were made. The images or other third party material in this article are included in the article's Creative Commons licence, unless indicated otherwise in a credit line to the material. If material is not included in the article's Creative Commons licence and your intended use is not permitted by statutory regulation or exceeds the permitted use, you will need to obtain permission directly from the copyright holder. To view a copy of this licence, visit http://creativeco mmons.org/licenses/by/4.0/. The Creative Commons Public Domain Dedication waiver (http://creativecommons.org/publicdomain/ zero/1.0/) applies to the data made available in this article, unless otherwise stated in a credit line to the data. 
in these patients, following recurrent malignancy [2]. The anthracycline antibiotic doxorubicin (Dox) is a very effective anti-cancer agent. However, up to 28 percent of treated patients occurred cardiovascular complications $[3,4]$. The major mechanism by which Dox induces cardiac damages involves disruption of DNA and RNA synthesis [5], oxidative damage via the formation of reactive oxygen species (ROS) [6], changes in mitochondrial membrane potential $\Delta \Psi \mathrm{m}$ [7], all above were the main reasons for cellular senescence [8]. Therefore, further exploration of the method alleviating Dox-induced cardiac senescence is warranted for the development of effective cardioprotective strategies.

Bone marrow-derived mesenchymal stem cells (BMMSCs) are an emerging and promising approach to treat cardiac injuries [9, 10]. However, limitations and challenges cannot be ignored when transplanting MSCs directly into target tissues. Studies have reported that the survival rate of transplanted stem cells is very low, hampering the transplantation efficiency and hence leading to impaired treatment effect $[11,12]$. There is mounting evidence that MSCs related repairment or regeneration of damaged cardiac tissues, primarily by means of exosomes release, which are safer and more effective [13]. At meanwhile, the contribution of exosomes to could be further improved though modifying MSCs [14]. When developing exosome-based therapeutics, exosomes were found to elicit differential effects on recipient cells depending on the cultural environment of parent cells [15]. These findings led to the search for a culture condition to optimize exosomes to be more efficient in treating Dox-induced cardiac injury. Migration inhibitory factor (MIF) is involved in multiple cardiac injuries, including cardiac senescence $[16,17]$. In older individuals, tolerance to ischemic stress is reduced, accompanied by impaired MIF expression. A previous study showed that regaining MIF function attenuated cardiac injury [18]. Beneficial cardioprotective effects of exosomes derived from MSCs have also been reported in the pretreatment with MIF [19]. Given the potential therapeutic benefits of exosomes derived from MSCs pretreated with MIF (exosome ${ }^{\mathrm{MIF}}$ ), whether MIF pretreatment could affect the functions of exosomes in treating Dox-related cardiac senescence process needs to be determined.

Intriguingly, the existence of long noncoding RNAs (lncRNAs) in exosomes has been reported, suggesting that lncRNAs may also be loaded with exosomes to regulate gene expression in host cells via cell-to-cell communication [20]. LncRNA-NEAT1 is located on chromosome 11 and has been indicated to play a significant role in the cardioprotective process through MSC-derived exosome transfer [19]. Besides, the participation of lncRNA-NEAT1 has been elucidated to be beneficial in the inhibition of Dox-induced cardiotoxicity and apoptosis [21]. Current insights into the molecular systems of lncRNA-miRNA regulatory interactions and implications in the treatment of Dox-induced cardiotoxicity allow a hypothesis that lncRNA-NEAT1 may be involved in the regulatory network of mRNA via competing endogenous RNAs (ceRNAs)-mediated miRNA evasion [22]. A target ceRNA of IncRNA-NEAT1, miR221-3p, impaired tissue regeneration through inhibiting the sirtuin (Sirt) family of proteins [23]. A previous study reported that exosome-transferred LncRNA-NEAT1 activated the Sirt protein family to exert a cardioprotective effect [19].

Therefore, the present study was performed to investigate the potential therapeutic effect of the exosome ${ }^{\mathrm{MIF}}$-transferred LncRNA-NEAT1, inhibited miR-221-3p, in Dox-induced cardiac senescence to provide a feasible therapeutic target for Dox-induced cardiotoxicity.

\section{Results}

\section{Exosome $^{\mathrm{MIF}}$ alleviated Dox-induced cardiac injury}

Eight-week-old mice received Dox treatment to simulate clinical chemotherapy (Fig. 1a). Echocardiography showed that left ventricular ejection fraction (EF) and fractional shortening (FS) significantly decreased, which was recovered by exosomes ${ }^{\mathrm{MIF}}$, in the Dox group compared with the control group. In contrast, the values in the exosome group indicated a therapeutic effect; however, it was not significant compared with the exosome ${ }^{\mathrm{MIF}}$ group (Fig. 1b-d). The expression of senescence-related and rejuvenation-related genes in mouse hearts were compared to confirm cellular senescence modulated by exosomes $^{\mathrm{MIF}}$ at the organ level. The expression levels of senescence-related genes $p 27, p 16$, and $p 21$ significantly increased (Fig. 1e-g), while the expression levels of rejuvenation-related genes Sirt1, Sirt2, and Sirt6 decreased (Fig. $1 \mathrm{~h}-\mathrm{j}$ ) in the Dox group compared with the Dox + exosome $^{\mathrm{MIF}}$ group.

\section{Exosome $^{\mathrm{MIF}}$ prevented the cardiac injury process mediated by LncRNA-NEAT1 transfer}

The microarray analysis between exosome and exosome $^{\mathrm{MIF}}$ was performed to determine whether exosomes could prevent the senescence process mediated by lncRNA. As shown in Fig. 2a, LncRNA-NEAT1 stood out as a candidate probably responsible for the anti-senescence effect. QRT-PCR further confirmed that LncRNA-NEAT1 was more abundant in exosome ${ }^{\mathrm{MIF}}$ (Fig. 2b). The siRNA targeting LncRNA-NEAT1 could downregulate the expression of LncRNA-NEAT1 in MSCs and exosomes (Fig. 2c, d). Exosome ${ }^{\mathrm{MIF}}$ attenuated 
the effects of Dox on cardiac function, and siRNALncRNA-NEAT1 blocked the function of exosome ${ }^{\mathrm{MIF}}$ (Fig. 2e-g). It also attenuated the inducement of Dox on senescent-related genes $p 27$ and $p 16$; the beneficial effects of exosomes were blocked by siRNA-LncRNA-NEAT1 (Fig. 2j, i). Cardiomyocytes were isolated from control and Dox-, Dox + exosome ${ }^{\mathrm{MIF}}$-, Dox + exosome $\mathrm{MIF}^{\mathrm{MiRNA}-}$ LncRNA-NEAT1 -, and Dox + exosome ${ }^{\text {MIF+siRNA-LncRNA-NT }}$ treated mice (Fig. 2j). SA- $\beta$-gal staining revealed more positive cells in Dox-treated than in control mouse hearts, while exosome ${ }^{\mathrm{MIF}}$ treatment recovered senescence. Moreover, silencing LncRNA-NEAT1 decreased the effect of exosome ${ }^{\mathrm{MIF}}$ (Fig. 2k, l).

\section{Exosome $\mathrm{MIF}^{\mathrm{MF}}$ treatment reduced Dox-related cardiac injury through inhibiting miR-221-3p}

Recent studies suggested the upregulation of miR-221-3p during the cellular senescence process [24]. The upregulation of this miR was also shown in Dox-treated hearts. However, this significant increase in miR-221-3p was reduced following exosome ${ }^{\mathrm{MIF}}$ treatment and blocked by siRNA-LncRNA-NEAT1 in MSCs, even in those treated with MIF (Fig. 3a). MiR-221-3p mimic transfection was performed in vivo to evaluate whether exosome $^{\mathrm{MIF}}$-induced miR-221-3p inhibition influenced cardiac senescence and cardiac function impaired by Dox (Fig. 3b). Echocardiographic data revealed that Doxtreated mice had significantly impaired cardiac function compared with control mice. However, exosome ${ }^{\mathrm{MIF}}$ showed a therapeutic effect, which was suppressed by miR-221-3p overexpression (Fig. 3c-e). Meanwhile, the expression levels of $p 27$ and $p 16$ mRNAs also decreased on treatment with exosome ${ }^{\mathrm{MIF}}$ (Fig. 3f, g). SA- $\beta$-gal staining results revealed that the number of senescent cardiomyocytes decreased in the exosome ${ }^{\mathrm{MIF}}$-treated group (Fig. 3h, i). These anti-senescent effects of exosome ${ }^{\mathrm{MIF}}$ were blocked by miR-221-3p mimic transfection.

\section{Exosome $^{\text {MIF }}$ had a better anti-senescent effect in cardiomyocytes treated with Dox}

Exosomes isolated from MSCs showed a round morphology and size of 50-100 nm, according to transmission electron microscope (TEM) (Additional file 1: Fig. S1A) and nanoparticle tracking analysis (NTA) (Additional file 1: Fig. S1B). At meanwhile, the exosome markers Flotillin-1 and CD81 were confirmed by western blot (Additional file 1: Fig. S1C). Considering the anti-senescent effect of MIF, whether MIF pretreatment showed a more cardioprotective effect in exosomes needed to be explored. The effects of exosome ${ }^{\mathrm{MIF}}$ on Dox-induced cardiomyocyte senescence were determined. The results showed that exosome ${ }^{\mathrm{MIF}}$ protected cardiomyocytes from senescence compared with Dox-treated cardiomyocytes, showing that more cells escaped from the G0/G1 phase as measured using flow cytometric analysis cell scan (FACS) (Fig. 4a, b), with the decreased expression of the cellular senescence-related genes $p 27$ and $p 16$ (Fig. 4ch), a lower percentage of SA- $\beta$-gal-positive cells (Fig. 4i, j), but an increase in telomere length and activity (Fig. 4k, l). However, exosomes from MSCs without any treatment also elicited cellular rejuvenation, however not as significant as with exosome $\mathrm{MIF}^{\mathrm{M}}$ indicating that pretreatment with MIF showed a better anti-senescent effect. At meanwhile, $48 \mathrm{~h}$ after Dox treatment, cellular apoptosis happened, exosome and exosome ${ }^{\mathrm{MIF}}$ both showed protective effect against apoptosis. However, exosomes from untreated MSCs showed less cellular protection, indicating that the observed effects were MIF-specific (Fig. 4m, n).

\section{Exosome $^{\mathrm{MIF}}$ inhibited cardiomyocyte senescence by delivering LnCRNA-NEAT1}

Notably, the increase in exosome ${ }^{\mathrm{MIF}}$-induced LncRNANEAT1 showed a significant therapeutic effect against Dox-related cardiac injury. Therefore, the subsequent mechanistic studies focused on LncRNA-NEAT1 in vitro. Exosomes prepared from MSCs were labeled with DiI to confirm whether this lncRNA could be transferred to cardiomyocytes through exosomes. Exosome uptake by cardiomyocytes was observed (Fig. 5a). Then, LncRNA-NEAT1 mRNA was detected in cardiomyocytes incubated with exosomes or exosome ${ }^{\mathrm{MIF}}$ compared with cardiomyocytes without any treatment; the untreated cardiomyocytes were used as control. As expected, LncRNA-NEAT1 had the strongest upregulation in cardiomyocytes incubated with exosome ${ }^{\mathrm{MIF}}$ (Fig. 5b). An siRNA-LncRNA-NEAT1 was constructed for silencing this lncRNA to further identify the antisenescent effect of LncRNA-NEAT1 transferred by exosome $^{\mathrm{MIF}}$. MSCs were transfected with siRNA against LncRNA-NEAT1 or control siRNA-NT and subjected to MIF. Then, exosomes were collected. Exosomes derived from siRNA against LncRNA-NEAT1 or control siRNA-NT in MSCs transfected and treated with MIF, or MSCs treated with only MIF, were added to cardiomyocytes. In parallel experiments, cardiomyocytes without any treatment were used as the control. QRT-PCR results suggested that exosome ${ }^{\mathrm{MIF}}$ transferred LncRNA-NEAT1 to cardiomyocytes, while silencing LncRNA-NEAT1 in MSCs blocked the transfer process (Fig. 5c).

In the subsequent experiments, exosome ${ }^{\mathrm{MIF}}$ significantly reduced the percentage of cells in the G0/G1 phase (Fig. 5d), expression of $p 27$ and $p 16$ (Fig. 5e, f), and number of SA- $\beta$-gal-positive cells (Fig. $5 \mathrm{~g}, \mathrm{~h}$ ). However, it elevated the telomere length and activity (Fig. $5 i, j$ ). This protective effect against Dox was inhibited by silencing 
a

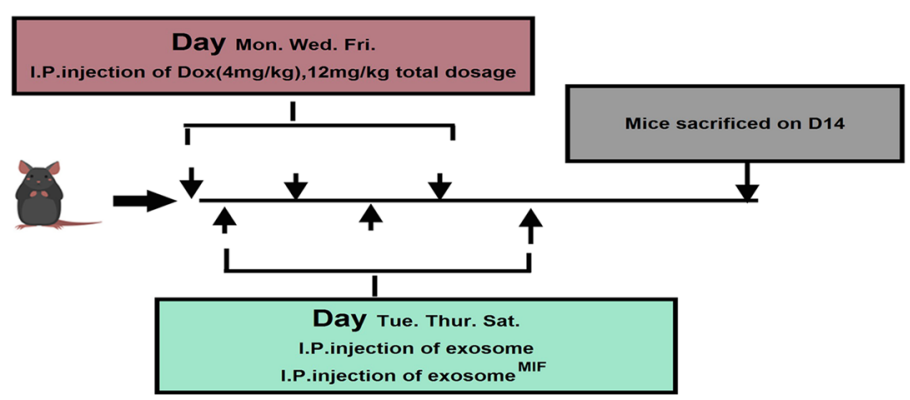

b

Control

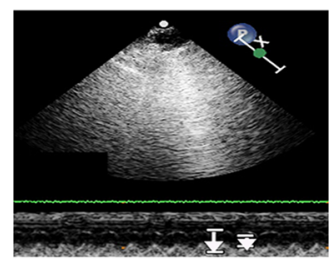

c

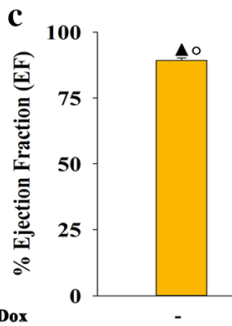

exosome

츨

exosome $^{\mathrm{MII}}$
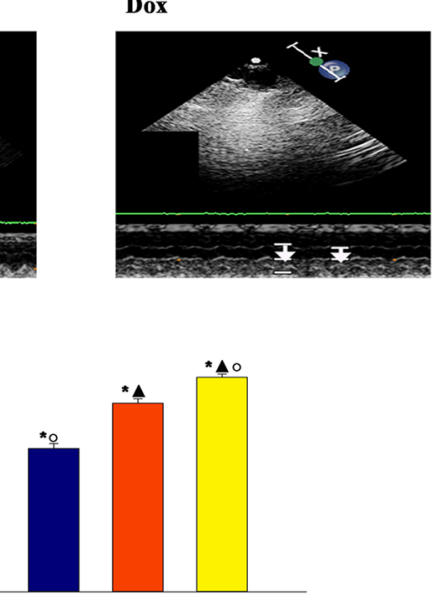

Dox+exosome

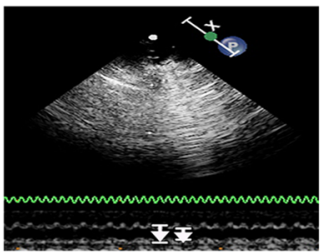

Dox+exosome ${ }^{\mathrm{MIF}}$

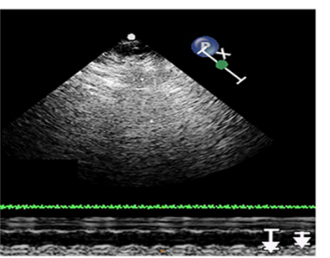

d
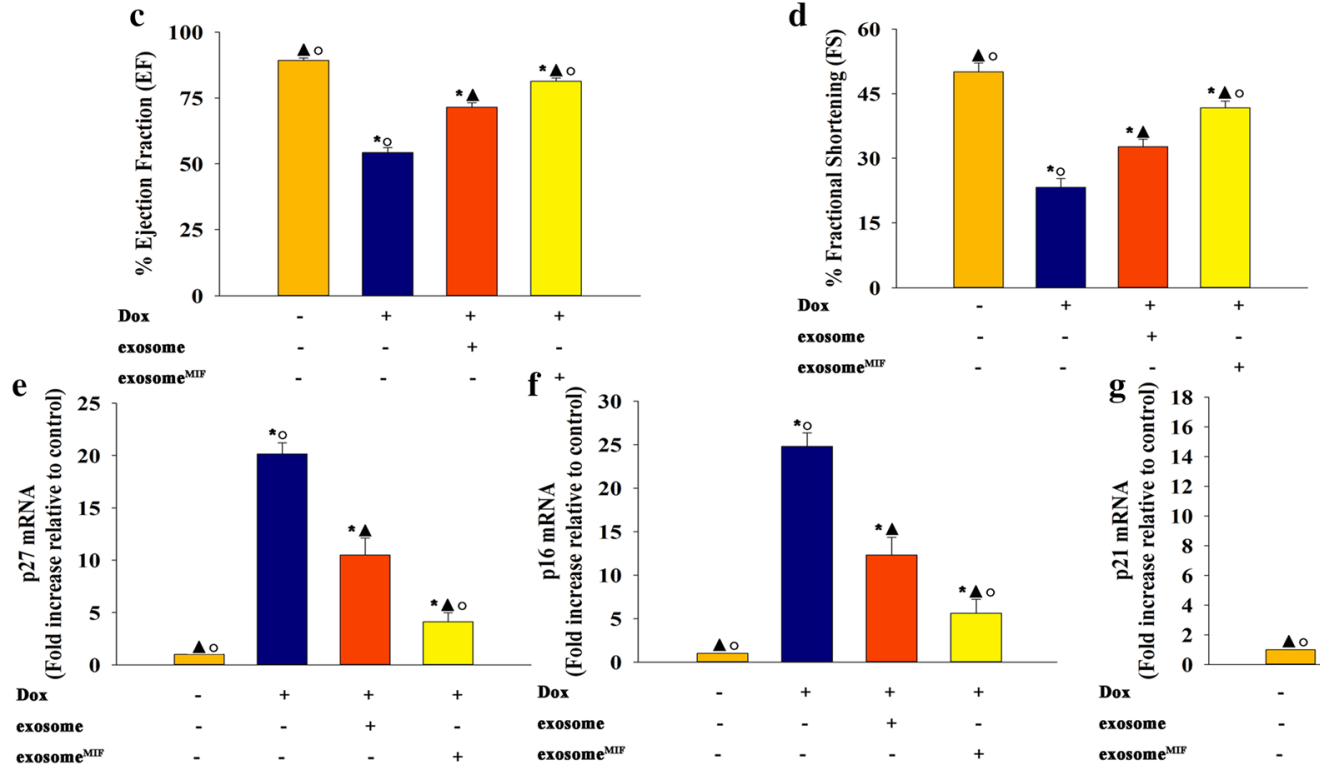

h

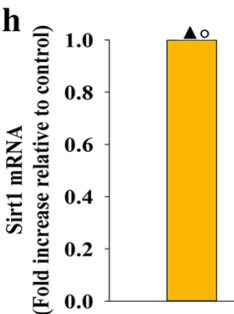

Dox

$-$

exosome $^{\mathrm{MIF}}$
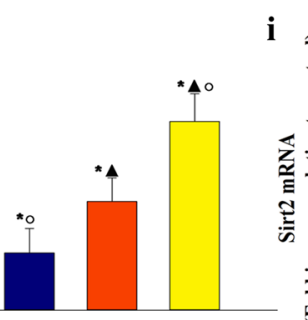

竞

Dox

exosome

exosome $^{\text {MIT }}$

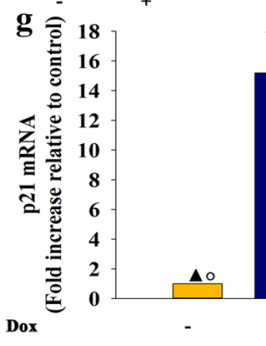

exosome

exosome $^{\mathrm{MIF}}$

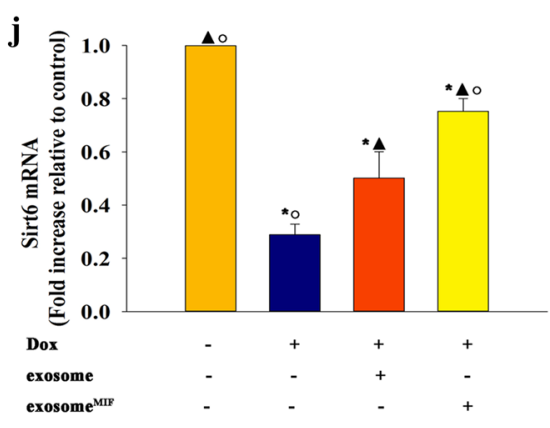

Fig. 1 Exosomes derived from MSCs pretreated with MIF alleviated Dox-induced cardiac injury. a The schema of the mice treatment. b Representative images of echocardiography exhibiting changes in cardiac function in each group. Echocardiographic analysis of ejection fraction (EF) c and fractional shortening (FS) $\mathbf{d}$ in week 2 after the first cycle of Dox, Dox + exosome, Dox + exosome ${ }^{\mathrm{MIF}}$, or control treatment. $\mathbf{e}-\mathbf{j}$ The expression of senescence-related genes p27 (E), p16 (f), and p21 (g), and rejuvenation-related genes Sirt1 (h), Sirt2 (i), and Sirt6 (j) in the aforementioned groups was examined using qRT-PCR. Each column represents the mean \pm SD of three independent experiments. * $P<0.05$ versus Control; $\boldsymbol{\Delta} P<0.05$ versus Dox; $\mathrm{P}<0.05$ versus Dox + exosome in one-way analysis of variance, $\mathrm{n}=3$ 

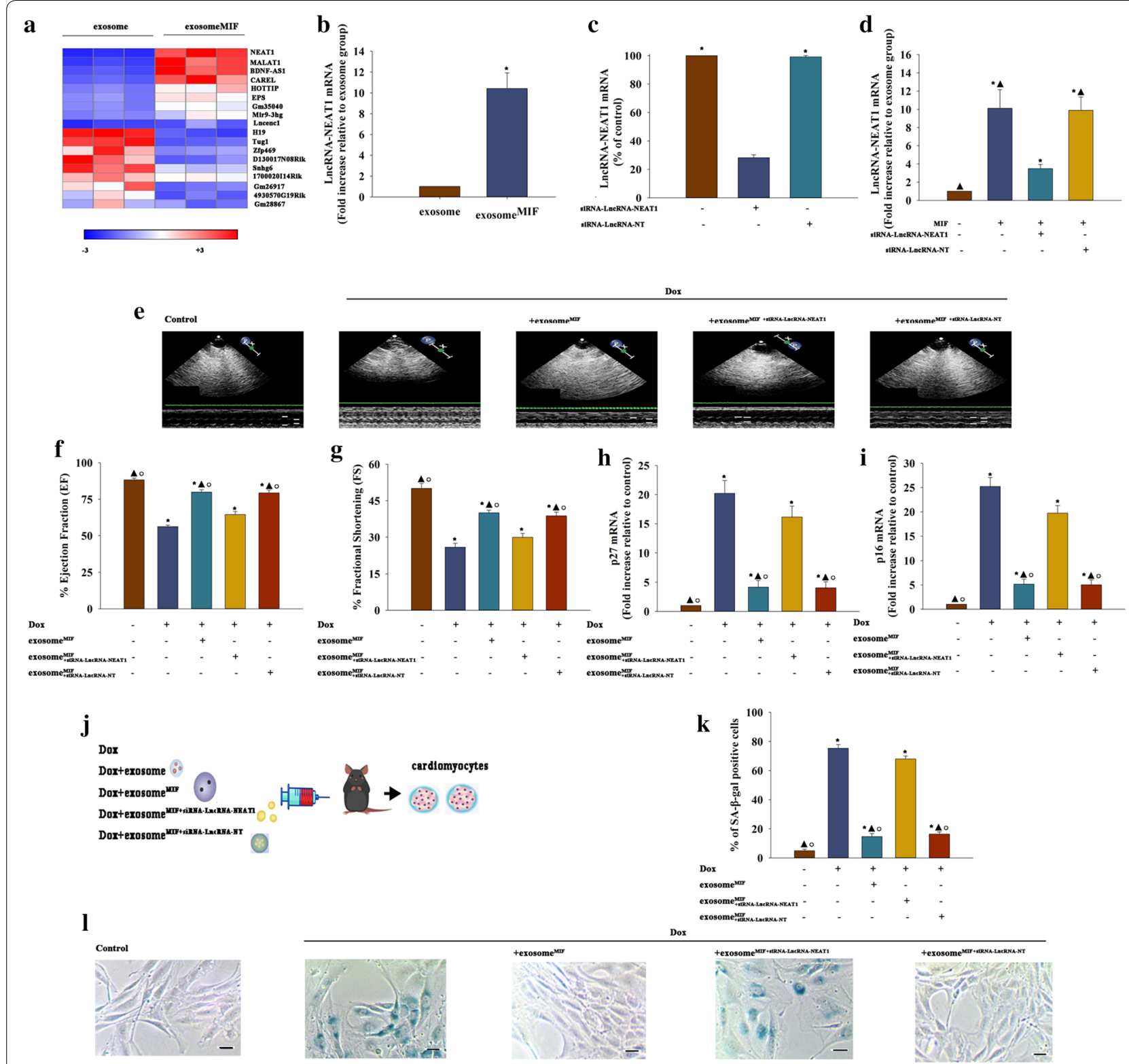

Fig. 2 Exosome ${ }^{\text {MIF }}$ prevented the cardiac injury process mediated by LncRNA-NEAT1 transfer. a Heat map of IncRNAs differentially expressed between exosome and exosome ${ }^{M I F}$. $\mathbf{b}$ LnCRNA-NEAT1 expression was validated by qRT-PCR in exosome and exosome ${ }^{\mathrm{MIF}}$. ${ }^{*} P<0.05 \mathrm{Vs}$ exosome in Student's t-test, $\mathrm{n}=3$. $\mathbf{c}$ LnCRNA-NEAT1 expression was validated by qRT-PCR in MSCs after LncRNA-NEAT1 silencing. ${ }^{*} P<0.05$ vs siRNALnCRNA-NEAT1 in repeated measures ANOVA, $n=3$. $\mathbf{d}$ LnCRNA-NEAT1 expression was validated by qRT-PCR in exosomes after silencing LncRNANEAT1 in MSCS. ${ }^{*} P<0.05$ vs Control; $\mathbf{A} P<0.05$ vs MIF + siRNA - LnCRNA-NEAT1 in repeated measures ANOVA, $\mathrm{n}=3$. e Representative images of echocardiography exhibiting the changes in cardiac function in each group. Echocardiographic analysis of EF (f) and FS (g). h, i p27 and p16 mRNA levels were analyzed using qRT-PCR. $\mathbf{j}$ Cardiomyocytes were isolated from control, Dox-, Dox + exosome ${ }^{\text {MIF }}-$, Dox + exosome ${ }^{\text {MIF }+ \text { siRNA- }}$ LnCRNA-NEAT1 -, and Dox + exosome ${ }^{M I F+s i R N A-L n c R N A-N T}$-treated mice. $\mathbf{k}$ Percentage of $\beta$-gal-positive cells. I Representative images of SA- $\beta$-gal staining. Each column represents mean \pm SD of three independent experiments. ${ }^{*} P<0.05$ versus Control; $\mathbf{\Delta} P<0.05$ versus Dox; ${ }^{O} P<0.05$ versus Dox + exosome MIF+SiRNA-LnCRNA-NEAT1 in one-way analysis of variance, $n=3$ 
LncRNA-NEAT1 in MSCs before treatment with MIF. These results supported that exosome ${ }^{\mathrm{MIF}}$ exerted an anti-senescent effect through direct LncRNA-NEAT1 transfer.

\section{LncRNA-NEAT1 transferred by exosome ${ }^{\mathrm{MIF}}$ sponged miR-221-3p against cardiomyocyte senescence}

Furthermore, the miRcode database was applied to predict the potential target miRNAs with a sequence complementary to that of LncRNA-NEAT1. LncRNANEAT1 contains the binding site for miR-221-3p, suggesting that lncRNA as a ceRNA sponged miR-221-3p to limit its function (Fig. 6a), which was confirmed by dualluciferase gene reporter assay. As illustrated in Fig. 6b, the co-transfection of miR-221-3p significantly inhibited the luciferase activities elicited by LncRNA-NEAT1. Further, a biotin-avidin pulldown system was employed to test whether miR-221-3p could pull down NEAT1. Cardiomyocytes were transfected with biotinylated miR-221-3p, then collected for biotin based pulldown assay. NEAT1 was pulled down as analyzed by qRT-PCR (Fig. 6c). To confirm whether exosomal derived LncRNANEAT1 acted as a ceRNA to sponge miR-221-3p, qRTPCR was applied to quantify the miR-221-3p expression. MiR-221-3p was induced by Dox in cardiomyocytes but substantially reduced by exosome ${ }^{\mathrm{MIF}}$. However, this repressive effect was impaired by exosome ${ }^{\mathrm{MIF}}$ derived from MSCs with silenced LncRNA-NEAT1 (Fig. 6d). Importantly, miR-221-3p overexpression (Fig. 6e) markedly increased the number of cells in the G0/G1 phase (Fig. 6f), expression of $p 27$ and $p 16$ (Fig. 6g, h), and number of SA- $\beta$-gal-positive cells (Fig. $6 \mathrm{i}, \mathrm{j}$ ), but inhibited the telomere and telomerase activity (Fig. 6k, l), even when exosome $^{\mathrm{MIF}}$ were added to Dox-treated cardiomyocytes (Fig. 6f-l).

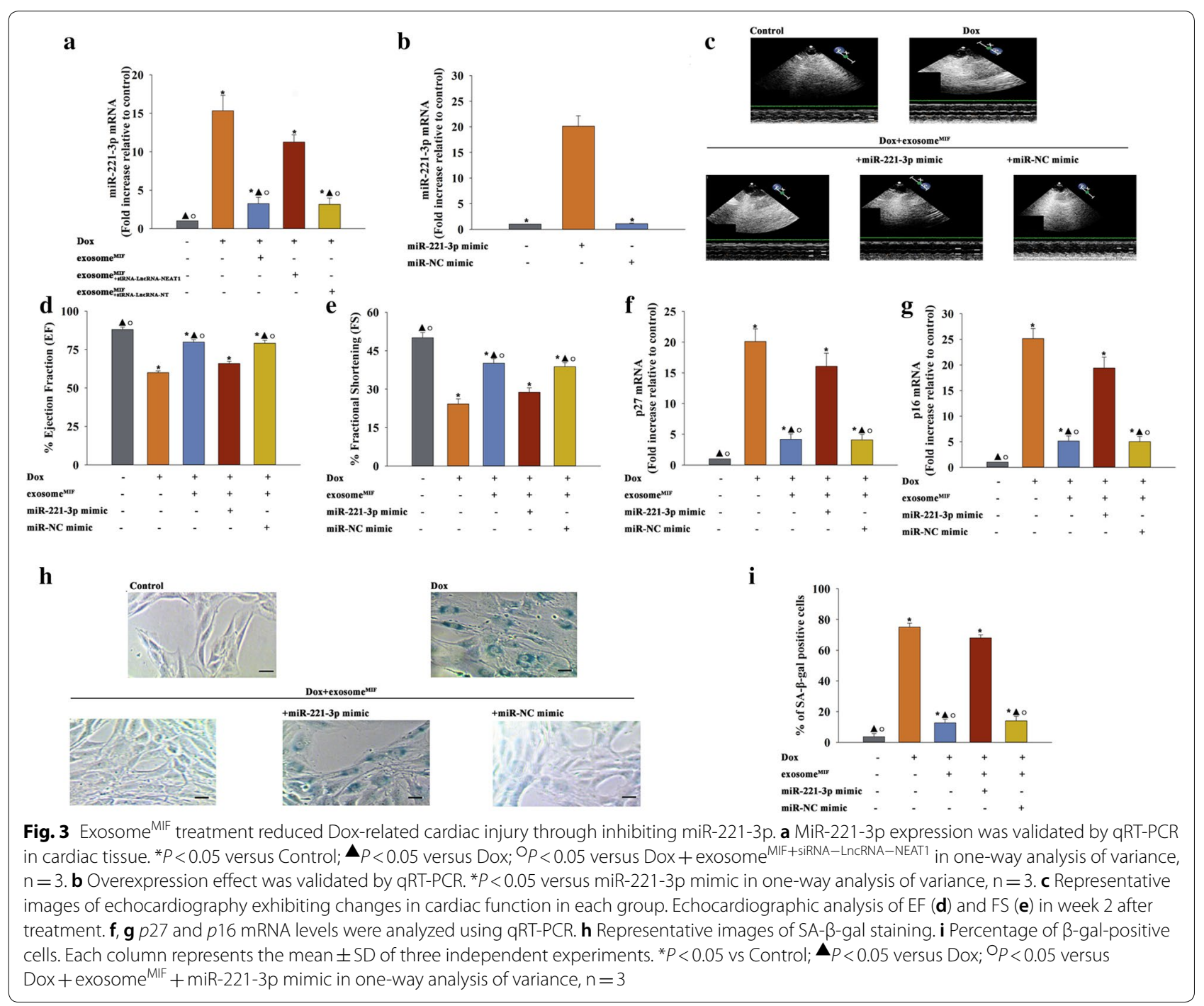




\section{MiR-221-3p shuttling by exosome ${ }^{\text {MIF }}$ reversed senescence through targeting Sirt2}

To better understand how exosome ${ }^{\mathrm{MIF}}$ modulated exosome $\mathrm{MIF}^{\mathrm{M}}$-induced cardiac senescence, the study focused on the target gene of miR-221-3p within cardiomyocytes. The database of miRNA targets indicated that Sirt2 might be the potential target relative to the anti-senescent effect. As shown in Additional file 2: Figure S2A, the 3'-UTR of Sirt2 contains a binding site for miR-221-3p. The dual-luciferase gene reporter assay revealed that the relative luciferase activity was significantly weakened in the Sirt2-WT + miR-221-3p mimic group (Additional file 2: Fig. S2B). As expected, Dox treatment markedly inhibited Sirt2 expression in cardiomyocytes, attenuated by exosome ${ }^{\mathrm{MIF}}$. In addition, elevating miR-221-3p expression impaired the expression of Sirt2 (Additional file 2: Fig. S2C and 2D). These results suggested that miR-221-3p inhibited the expression of Sirt 2 via post-transcriptional regulation. This study further investigated the mechanism underlying the crosstalk between Sirt 2 and exosome ${ }^{\mathrm{MIF}}$ in Doxinduced cellular senescence by silencing Sirt2 using siRNA. Sirt 2 mRNA and protein expression levels were significantly reduced in cells transfected with siRNASirt2 compared with cells transfected with nontargeting siRNA (siRNA-NT) as the control (Fig. 7a-c). Sirt2 silencing markedly increased the number of cells in the G0/G1 phase (Fig. 7d), expression of $p 27$ and $p 16$ (Fig. 7e, f), and number of SA- $\beta$-gal-positive cells (Fig. $7 \mathrm{~g}, \mathrm{~h}$ ), but impaired the telomere length and telomerase activity (7I and J), even when exosome ${ }^{\mathrm{MIF}}$ were added to Dox-treated cardiomyocytes.

\section{Discussion}

Dox is one of the most potent broad-spectrum antitumor anthracycline antibiotics commonly used to treat a variety of cancers [25]. However, the clinical use of Dox is limited because of its serious cardiotoxicity, which often leads to irreversible degenerative cardiomyopathy and heart failure [26]. The most common complications of Dox cardiotoxicity are left ventricular dysfunction [3], coincidence with the findings of this study showing that Dox treatment impaired left ventricular function, accompanied by lower EF and FS values. The mechanism of Dox-induced cardiotoxicity involves the disruption of DNA and RNA synthesis, eventually leading to cell senescence [27]. In the present study, the cellular senescence-dependent increase in Dox-induced cardiac dysfunction was associated with increased cell cycle arrest, which is the main phenotype of the disruption of DNA and RNA synthesis and senescence of cardiomyocytes [28].

Substantial evidence is available showing that stem cells exert their therapeutic effect via the secretion of soluble factors and the production of exosomes [29]. The content in exosomes may vary depending on the physiological and pathological states of culture conditions [30]. This study showed that MIF activation contributed to modifying exosomes ${ }^{\mathrm{MIF}}$ derived from MSCs to exert the anti-senescent effect after Dox-induced cardiac injury. In addition, exosomes ${ }^{\mathrm{MIF}}$ recovered the telomere length and activity, which were important in heart regeneration [31]. Exosomes alone showed a therapeutic effect to some extent [32]. However, it is conceivable that exosomes related to better anti-senescent effects might be mediated by treatment with anti-senescent and cardioprotective factor MIF.

A number of recent studies have revealed that lncRNAs play an important role in senescence-related cardiac injury [33]. Some lncRNAs contained in exosomes serve as important messages to alter gene expression and cellular functions of distant organs, usually acting as regulators in many cardiac pathological processes [14]. Modifying a cell culture environment, leading to changes in components of lncRNAs, and investigating the molecular and biological functions of lncRNAs are important in providing new insights into the treatment of Dox-induced cardiac injury. The results suggested that MIF pretreatment induced LncRNA-NEAT1 accumulation in exosome $\mathrm{MIF}^{\mathrm{MIF}}$ derived from MSCs, with a significant anti-senescent effect against Dox-induced cardiac injury. LncRNA-NEAT1 is a 2.1-kb lncRNA transcribed from the NEAT1 gene [34]. NEAT1 is important for gene stability [35]. A previous study showed that Dox promoted cellular damage though impairing gene stability [36]. Moreover, silencing lncRNA-NEAT1 in MSCs, even MSCs treated with MIF, could not exert a cardioprotective effect, with shortened telomere length and impaired telomerase activity, both important in gene stability [37].

In recent years, emerging evidence suggested that lncRNAs served mainly as a miRNA sponge to exert their post-transcriptional functions as ceRNAs, which is

(See figure on next page.)

Fig. 4 Exosome ElF had a better anti-senescent effect in cardiomyocytes treated with Dox. a, b Cell cycle distribution was analyzed. c, d p27 and p16 mRNA levels were analyzed using qRT-PCR. e-h p27 and p16 protein levels were analyzed using western blot analysis. i Representative images of SA- $\beta$-gal staining. $\mathbf{j}$ Percentage of $\beta$-gal-positive cells. $\mathbf{k}$ The Telomere length was analyzed by qRT-PCR. I Relative telomerase activity was measured. $\mathbf{m}, \mathbf{n}$ Representative flow cytometric dot plots of apoptotic cells after Annexin V/propidium iodide staining. ${ }^{*} P<0.05$ versus Control; $\boldsymbol{\Delta} P<0.05$ versus Dox; $\mathrm{O} p<0.05$ versus Dox + exosome in repeated measures ANOVA, $\mathrm{n}=3$ 


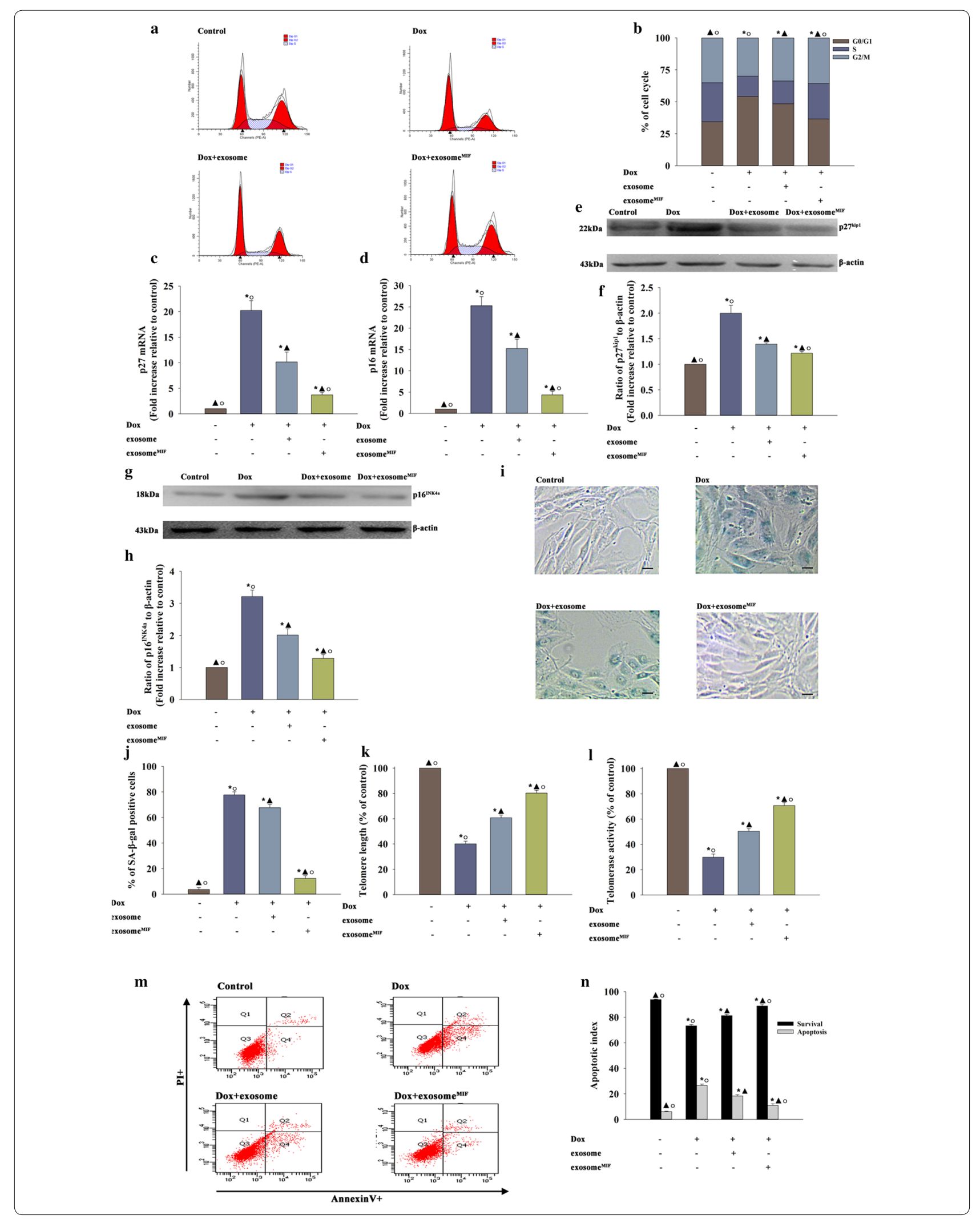




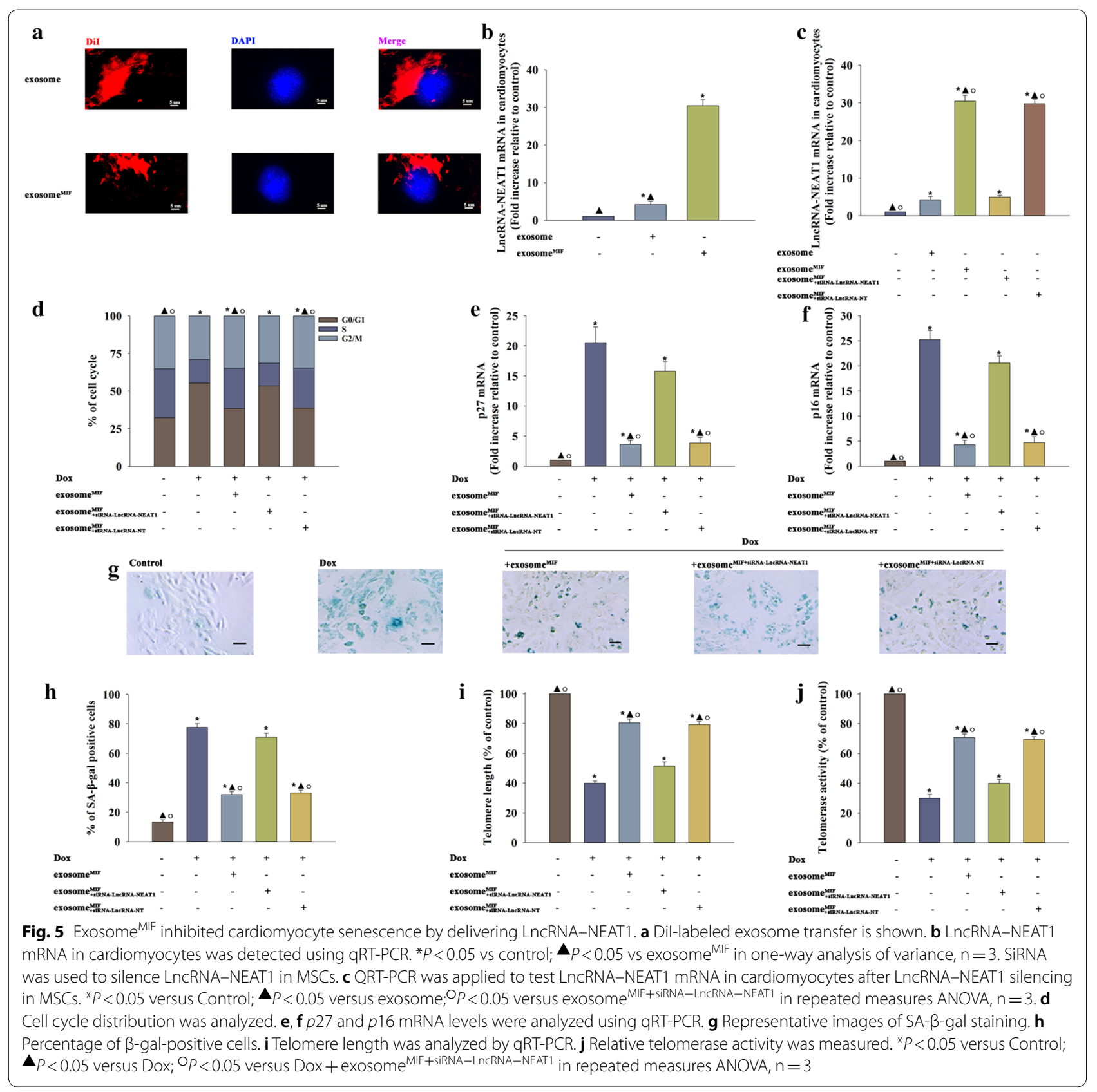

more effective than the traditional anti-miRNA approach [38]. Accordingly, starBase database prediction and dualluciferase reporter gene assay suggested that exosome $\mathrm{MIF}^{\mathrm{MF}}$ exerted an anti-senescent effect against Dox in vitro by inhibiting miR-221-3p expression, thus influencing the expression of the downstream gene Sirt2. Mir-221-3p was notably activated in the age-related degeneration diseases [39]. MiR-221-3p is enriched in aged cardiac tissue, thus leading to age-related cardiac injury [40]. Dox induced cardiac senescence accompanied by elevated levels of
miR-221-3p in the cardiac tissue, while this elevation of miR-221-3p was reversed by exosomes ${ }^{\mathrm{MIF}}$, through transferring LncRNA-NEAT1. Previous studies proposed that miR-221-3p upregulation during replicative senescence acted in concert to induce cell cycle phase arrest and telomere erosion, establishing a senescent phenotype [24]. In our research, overexpression of miR-221-3p not only re-settled the cell cycle, but also shortened the telomere length and inactivated the telomerase activity, which were recovered by exosomes ${ }^{\mathrm{MIF}}$. 


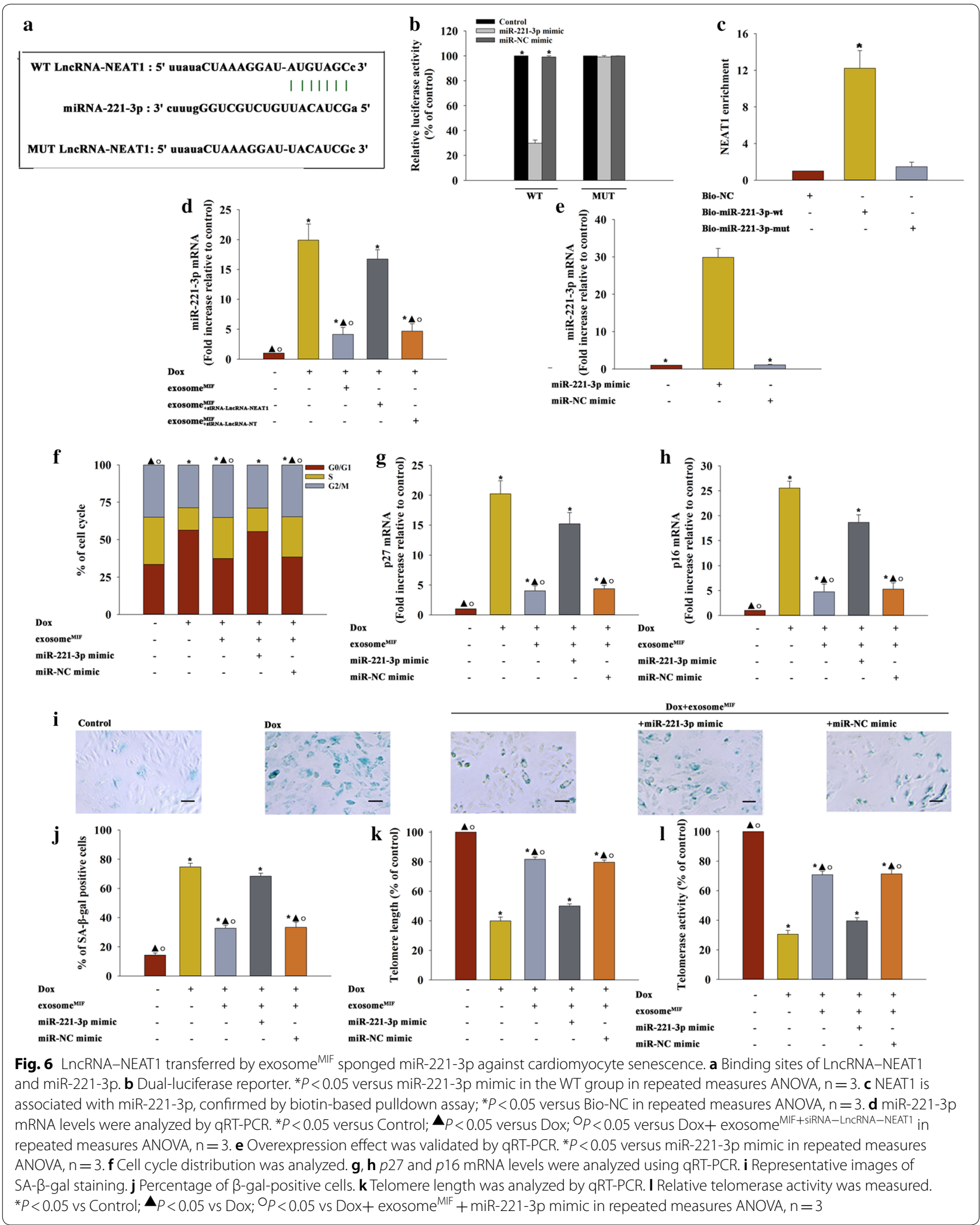




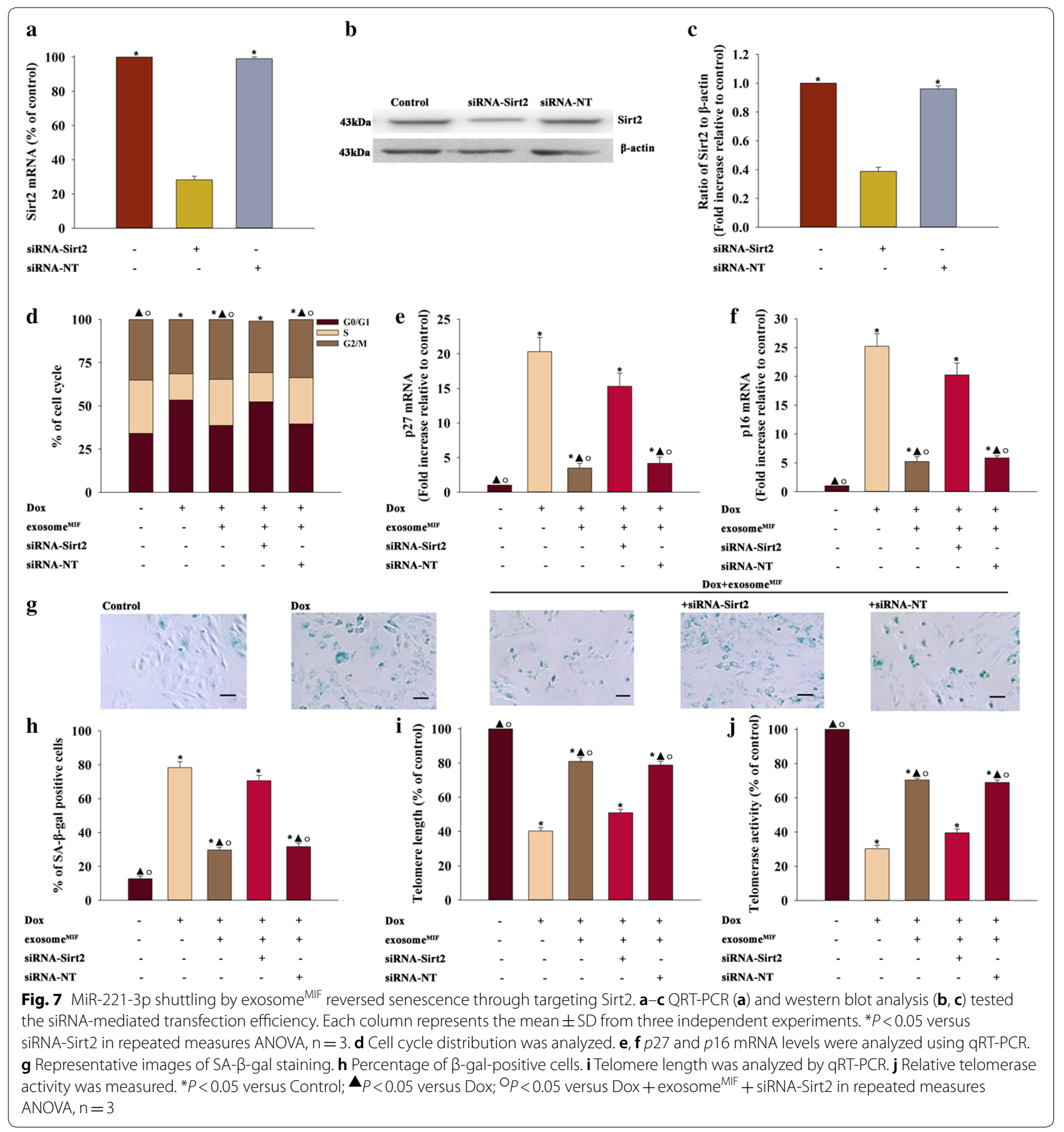

In this study, the bioinformatics analysis showed that miR-221-3p interacted with the $3^{\prime}$-UTR of Sirt 2 and suppressed Sirt2 expression at the post-transcriptional level, which was confirmed by the results of the luciferase reporter assay. Aging is one of the key risk factors for cardiac injury; the Sirt modulate lifespan in species ranging from yeast to mammals [41, 42]. Sirt are a class of deacetylase enzymes that play an important role in tissue regeneration [43]. Sirt2 has been largely studied in the context of aging and aging-associated diseases [44]. Sirt2 deficiency is known to promote genomic instability, which is an important event in cellular senescence [45]. The 
present study also found that Sirt2 silencing impaired the anti-senescent effect of exosomes ${ }^{\mathrm{MIF}}$. Sirt2 has been suggested as an AMP-Activated Protein Kinases (AMPK) activator, thus alleviating age-related cardiac hypotrophy [46]. Meanwhile, AMPK activation could attenuate Doxinduced cardiotoxicity [47]. A previous study found that MIF could exert a rejuvenation effect through AMPK activation [48]. These findings suggested that Sirt2 took part in exosome ${ }^{\mathrm{MIF}}$ against Dox-induced cardiac injury.

Some limitations existed in the current study. First, only LncRNA-NEAT1 in exosome ${ }^{\mathrm{MIF}}$ was explored. Further investigation is required to explore the functions of other LncRNAs which are significantly changed in exosome $^{\mathrm{MIF}}$. Second, it would be important to confirm exosome $^{\mathrm{MIF}}$ dependent biological pathways also in heart tissue of model of tumor. Last but not least, miR-221-3p $\mathrm{KO}$ animal will be applied to verify our findings in the future study.

\section{Conclusions}

The present study demonstrated that exosome ${ }^{\mathrm{MIF}}$ relieved Dox-induced cardiomyocyte senescence, and these beneficial effects were mediated by the novel exosome/lncRNA-NEAT1/miR-221-3p/Sirt2 pathway. Hence, it proposed a novel ceRNA signaling pathway to optimize the stem cell-based anti-senescent effect. Given that exosomes are easy to obtain, exosome-mediated therapy represents a potentially useful approach for clinical applications in Dox-induced cardiac injury.

\section{Materials and methods}

\section{Animals}

Male C57/Bl6 mice were maintained in accordance with the guidelines published by the US National Institutes of Health. All study procedures were approved by the Institutional Animal Care and Use Committee of Wenzhou Medical University (IRB Approval Number: wydw 20190491). This study was conducted in compliance with the Guide for the Care and Use of Laboratory Animals published by the National Academy Press (NIH, revised in 1996).

\section{Treatment using Dox and exosome $\mathrm{MIF}^{\mathrm{MI}}$ in vivo}

In eight-week-old male C57/Bl6 mice, Dox was injected in three intraperitoneal (i.p.) injections $(4 \mathrm{mg} / \mathrm{kg}$ body weight) on alternative days in a time span of 1 week (Monday, Wednesday, and Friday) for a cumulative dose of $12 \mathrm{mg} / \mathrm{kg}$. For exosome $\mathrm{MIF}^{\mathrm{M}}$ treatment groups, exosome $^{\mathrm{MIF}}$ were injected (i.p.) on alternative days between Dox treatments (Tuesday, Thursday, and Saturday), as previously reported [32]. After the experiments, mice were sacrificed by $\mathrm{CO}_{2}$ inhalation. The investigator was blinded to the group allocation during the experiment.

\section{Echocardiographic evaluation}

For echocardiography, 14 days after treatment with Dox, mice were anesthetized with 1.5-2\% isoflurane and kept warm on a heated platform. The vital signs were monitored during echo. The vevo 2100 was used to observe the echocardiographic parameters of mice and assess the cardiac functions (Vevo 2100, Visual Sonics, Canada).

\section{Quantitative reverse transcription-polymerase chain reaction (qRT-PCR)}

RNA was isolated using TRIzol reagent (Invitrogen, CA, USA), and cDNA was synthesized using an ImProm-II reverse transcription kit (Promega, WI, USA) following the manufacturer's instructions. Quantitative reverse transcription-polymerase chain reaction (qRT-PCR) was performed with SYBR Green to detect mRNA levels. The mRNA levels were calculated relative to the control Gapdh or U6 using the $2^{-\Delta \Delta C q}$ method. The sequences of all qRT-PCR primers are shown in Table 1.

\section{Microarray analysis}

Exosomes derived from MSCs, or MSCs treated with MIF, were lysed immediately in $500 \mu \mathrm{L}$ of TRIzol reagent (ThermoFisher Scientific, MA, USA) and stored at $-80{ }^{\circ} \mathrm{C}$ before purification using a standard phenolchloroform extraction protocol with an RNAqueous Micro Kit (ThermoFisher Scientific). The transcriptome was subjected to microarray analysis using an Affymetrix human array (ThermoFisher Scientific) and normalized based on quantiles.

\section{Western blot analysis}

Western Blot analysis was conducted as previously described [49]. Primary antibodies, including p27 $7^{\text {kip }}$ (ab62364), p16 ${ }^{\mathrm{INK} 4 \mathrm{a}}$ (ab211542), Flotillin-1 (ab41927), CD81 (ab109201), Sirt2 (ab211033), and $\beta$-actin (ab179467), were purchased from Abcam.

\section{Cardiomyocyte isolation and culture}

Mouse ventricular myocytes were isolated from C57BL/6 mice. The animals were euthanized by cervical dislocation. The hearts were obtained and digested in a digestion solution containing $0.25 \%$ trypsin and collagenase I. Myocytes were separated after $3 \mathrm{~h}$ of differential sedimentation and adhesion. They were then cultured in lowglucose Dulbecco's modified Eagle's medium (DMEM) containing $10 \%$ fetal bovine serum (FBS). 


\section{Senescence-associated $\beta$-galactosidase assay (SA- $\beta$-gal} assay)

The cellular senescence was measured using the SA- $\beta$ gal assay (Cell Signaling Technology, MA, USA). Briefly, the cells at the density of $2 \times 10^{4}$ were fixed with $2 \%$ paraformaldehyde and incubated with the SA- $\beta$-gal staining solution as previously described [50].

\section{Agomir studies}

Chemically modified oligonucleotides were designed to mimic miR-221-3p. Eight-week-old male C57/Bl6 mice were injected (intraperitoneally) with agomir-221-3p $(80 \mathrm{mg} / \mathrm{kg})$ or control agomir $(80 \mathrm{mg} / \mathrm{kg})$ for three consecutive days as previously reported [51].

\section{Cell culture and cell treatment}

BM-MSCs were isolated using a standard protocol, as described previously [52]. Briefly, bone marrow was isolated from the femur and tibia of mice by flushing with PBS. Adherent MSCs were propagated and maintained at $37^{\circ} \mathrm{C}$ and in the presence of $5 \% \mathrm{CO}_{2}$ in high-glucose DMEM supplemented with $10 \%$ FBS and $1 \%$ penicillin/ streptomycin.

For MIF treatment, the cells were cultured with a medium containing $100 \mathrm{ng} / \mathrm{mL}$ of recombinant MIF and incubated at $37{ }^{\circ} \mathrm{C}$ for various periods as previously reported [48].

HL-1 murine cardiomyocytes were maintained in fibronectin-coated flasks, supplemented with 10\% FBS, $100 \mathrm{U} / \mathrm{mL}$ penicillin, $100 \mathrm{mg} / \mathrm{mL}$ streptomycin, and $2 \mathrm{mM}$ L-glutamine, and kept semi-confluent at all times.

\section{Isolation of exosomes}

Exosomes were isolated and purified from the supernatants of MSCs and MIF-treated MSCs. The supernatants were collected after 48 -h culture. The exosome quick extraction solution was added to the filtered solution at a 1:5 ratio and stored at $4{ }^{\circ} \mathrm{C}$ for at least $12 \mathrm{~h}$. The precipitation (exosomes) was dissolved in PBS and stored at $-70{ }^{\circ} \mathrm{C}$. The characterization of exosomes was carried out as previously reported [19].

\section{Cell cycle assay}

Cold anhydrous ethanol (70\%) was employed to fix the cells. Then, the cells were treated with propidium iodide (Sigma, MO, USA) and RNase A. A flow cytometer equipped with CellQuest software was used to detect the cell cycle distribution.

\section{Relative telomere length measurement}

Relative telomere length quantification in HL-1 cells was performed using a qPCR approach based on a previously
Table. 1 Primer sequences

\begin{tabular}{|c|c|}
\hline Genes & Sequences \\
\hline \multirow[t]{2}{*}{ p27 } & F: $5^{\prime}-C C T G G A G C G G A T G G A C G C C A G A C A-3^{\prime}$ \\
\hline & R: 5'-CACCAAATGCCGGTCCTCAGAGTT-3' \\
\hline \multirow[t]{2}{*}{ p16 } & F: 5'-TTG GCC CAA GAG CGG GGA CA-3' \\
\hline & R: 5'-GCG GGC TGA GGC CGG ATTTA-3' \\
\hline \multirow[t]{2}{*}{ p21 } & F: 5'-TCCACAGCGATATCCAGACA-3' \\
\hline & R: 5'-GGACATCACAGGATTGGAC-3' \\
\hline \multirow[t]{2}{*}{ Sirt1 } & F: 5'-TTGGCACC GATCCTCGAAC-3' \\
\hline & R: 5'-CCCAGCTCCAGTCAGAACTAT-3' \\
\hline \multirow[t]{2}{*}{ Sirt2 } & F: $5^{\prime}$-TGAATGGCACCTACAGAGAC-3' \\
\hline & R: 5'-CAAAGGCATTATGGTAGGGC-3' \\
\hline \multirow[t]{2}{*}{ Sirt6 } & F: 5'-AGTTCGACACCACCTTTGAG-3' \\
\hline & R: 5'-CGTACTGCGTCTTACACTTG-3' \\
\hline \multirow[t]{2}{*}{ LncRNA-NEAT1 } & F: 5'-TTGGGACAGTGGACGTGTG-3' \\
\hline & 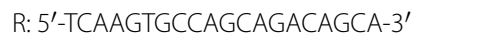 \\
\hline \multirow[t]{2}{*}{$\operatorname{miR}-221-3 p$} & F: 5'-GGGAAGCTACATTGTCTGC-3' \\
\hline & R: 5'-CAGTGCGTGTCGTGGAGT-3' \\
\hline \multirow[t]{2}{*}{ Telomere length } & F: 5'-TGAAAGTAGAGGATTGCCACTG-3' \\
\hline & R: 5'-AGCCAGAACAGGAACGTAGC-3' \\
\hline \multirow[t]{2}{*}{ GAPDH } & F: 5'-GGA GCC AAA AGG GTC ATC AT-3' \\
\hline & R: 5'-GTG ATG GCA TGG ACT GTG GT-3' \\
\hline \multirow[t]{2}{*}{ U6 } & F: 5'-CTCGCTTCGGCAGCACA-3' \\
\hline & R: 5'-AACGCTTCACGAATTTGCGT-3' \\
\hline siRNA-LnCRNA-NEAT1 & 5'-TACCATCAGCCTTTAG-3' \\
\hline siRNA-LncRNA-NT & 5'-AACACGTCTATACGC-3' \\
\hline siRNA-Sirt2 & 5'-GCAGCUUGUGUGAGCUCAATT-3' \\
\hline siRNA-NT & 5'-UUGAGCUCACACAAGCUGCTT-3' \\
\hline
\end{tabular}

established method [53], using Gapdh as the normalizing gene. The primer pairs used to detect the telomere length are listed in Table 1.

\section{Relative telomerase activity measurement}

The telomerase activity of HL-1 cells was examined using a Telo TAGGG Telomerase PCR Enzyme-linked immunosorbent assayPlus kit according to the manufacturer's instructions as described previously [54].

\section{Flow cytometric analysis of cell apoptosis}

Annexin V-FITC Apoptosis Detection Kit was applied to test cellular apoptosis, according to manufacturer's protocol. Briefly, harvested cells were resuspended in $300 \mu \mathrm{L}$ binding buffer, and incubated with $5 \mu \mathrm{L}$ Annexin V-fluorescein isothiocyanate (FITC) solution for $30 \mathrm{~min}$ at $4^{\circ} \mathrm{C}$ in dark conditions, followed by further incubation in $5 \mu \mathrm{L}$ propidium iodide for $5 \mathrm{~min}$. The cells were then analyzed immediately by bivariate flow cytometry using a 
BD FACSCanto II equipped with BD FACSDiva Software (Becton-Dickinson, San Jose, CA, USA).

\section{Fluorescence tracing of exosomes in vitro}

Exosomes were labeled with DiI incubated with the dye $(1 \mathrm{mM})$ at the volume ratio of $500: 1$ for $30 \mathrm{~min}$, followed by exosome isolation. For the in vitro tracing of exosomes, cardiomyocytes were incubated with DiIlabeled exosomes for $3 \mathrm{~h}$. The cell nuclei were stained with DAPI (1:1000, Invitrogen) for $10 \mathrm{~min}$ at $37^{\circ} \mathrm{C}$. Fluorescence was detected under a microscope.

\section{Small interfering RNA transfection}

LncRNA-NEAT1 expression in MSCs was knocked down using small interfering (si)RNAs, with a nontargeting siRNA as a negative control (Invitrogen). Sirt2 expression in cardiomyocytes was also knocked down using siRNAs. The procedures were conducted as described previously [54]. The transfection efficiency was detected using qRTPCR and western blot analysis.

\section{MiR-221-3p overexpression}

Cardiomyocytes were seeded into six-well plates at a density of $1 \times 10^{5}$ cells per well. The cells were transfected with miR-221-3p mimic or negative control (NC) mimic (Pre-miR miRNA Precursors, Life Technologies, Karlsruhe, Germany) using X-treme transfection reagent (Roche Applied Science, Penzberg, Germany), according to the manufacturer's protocol, to induce the overexpression of miR-221-3p. The cells were harvested for further analysis $48 \mathrm{~h}$ after transfection, and the transfection efficiency was analyzed using qRT-PCR.

\section{Pulldown assay with biotinylated miRNA}

Cardiomyocytes were transfected with biotinylated miRNA, collected $48 \mathrm{~h}$ after transfection. The cell lysates were incubated with M-280 streptaviden magnetic beads (Invitrogen, San Diego, CA, USA) as described previously $[55,56]$. RT-qPCR was applied to analyze the bound RNAs, purified using TRIzol reagent (Invitrogen).

\section{Luciferase reporter assay}

The 3'-untranslated regions (UTRs) of LncRNA-NEAT1 and Sirt 2 were synthesized, annealed, and inserted into the SacI and HindIII sites of the pmiR-reporter luciferase vector (Ambion), downstream of the luciferase stop codon to induce the mutagenesis of LncRNA-NEAT1 and Sirt2. The constructs were validated by sequencing. Cardiomyocytes were seeded into a 24-well plate for luciferase assay. After overnight culture, the cells were co-transfected with a wild-type (WT) or mutant plasmid and an equal amount of miR-221-3p mimic or miR-NC mimic. Luciferase assays were performed using a dualluciferase reporter assay system (Promega) $24 \mathrm{~h}$ after transfection.

\section{Statistical analysis}

Data were expressed as the mean \pm standard deviation (SD). Differences between groups were tested by one-way analysis of variance, and comparisons between the two groups were evaluated using the Student's $t$ test. Analyses were performed using SPSS package v19.0 (SPSS Inc., IL, USA). A $P$ value less than 0.05 was considered statistically significant.

\section{Supplementary information}

Supplementary information accompanies this paper at https://doi. org/10.1186/s12951-020-00716-0.

Additional file 1: Figure. S1. Confirmation of exosomal collection. The exosome was characterized by TEM (A), NTA (B), and western blot (C).

Additional file 2: Figure S2. MiR-221-3p directly targeted Sirt2. (A) Binding sites of miR-221-3p and the Sirt2 3'-UTR. (B) Dual-luciferase reporter was applied in cardiomyocytes after co-transfection with miR-221-3p mimic, miR-NC mimic, and Sirt2 3'-UTR wild-type (WT) or mutant (MUT) plasmids. ${ }^{*} P<0.05$ versus the miR-221-3p mimic in the WT group in repeated measures ANOVA, $n=3$. (C and D) Sirt2 and $\beta$-actin protein levels were confirmed using western blot analysis in cardiomyocytes. Untreated cardiomyocytes were used as control. ${ }^{*} P<0.05$ versus Control; $\boldsymbol{\Delta}_{P}<0.05$ versus Dox; $\mathrm{O}<0.05$ versus Dox + exosome $^{\mathrm{MIF}}+\mathrm{miR}^{2} 221-3 p$ mimic in repeated measures ANOVA, $n=3$.

\section{Abbreviations}

AMPK: AMP-activated protein kinases; ceRNAs: Competing endogenous RNAs; DIC: Dox-induced cardiomyopathy; DMEM: Dulbecco's modified Eagle's medium; Dox: Doxorubicin; EF: Ejection fraction; FBS: Fetal bovine serum; FACS: Flow cytometric analysis cell scan; FS: Fractional shortening; IncRNAs: Long non-coding RNAs; MIF: Macrophage migration inhibitory factor; MSCs: Mesenchymal stem cells; miR: microRNA; NEAT1: Nuclear paraspeckle assembly transcript 1; qRT-PCR: Quantitative reverse transcription-polymerase chain reaction; ROS: REACTIVE oxygen species; SA- $\beta$-gal assay: Senescence-associated $\beta$-galactosidase assay; SD: Standard deviation; siRNA: Small interfering RNA; Sirt2: Sirtuin 2; 3'-UTRs: 3'-Untranslated regions.

\section{Acknowledgements}

We thank Dr. Huijia Zhu for her expert assistance with echo experimental design and excellent technical assistance. We also thank Dr. Fengming Kong for her expert assistance with biostatistics assistance.

\section{Authors' contributions}

LZ: Provision of study material; collection and/or assembly of data; data analysis and interpretation. WX: Conception and design; collection and/or assembly of data; Data analysis and interpretation. DC: Data analysis and interpretation; manuscript writing. YY: Collection and/or assembly of data; data analysis and interpretation. TH: Collection and/or assembly of data; data analysis and interpretation. SL: Conception and design; financial support; administrative support; MH: Conception and design; manuscript writing; final Approval of manuscript. All authors read and approved the final manuscript.

\section{Funding}

The present study was supported by the National Natural Science Foundation of China (Grant Nos. 82071561 to MH; Grant Nos. 81974186; 81671205 to STL), the Science and Technology Planning Project of Wenzhou (Grant Nos. Y2020735 to MH; Grant No. Y20190445, Y2020928 to LZ), and the Medical 
Science and Technology Project of Zhejiang Province (Grant No. 2018KY517 to $\mathrm{MH}$ ).

\section{Availability of supporting data}

All data and materials are available in the manuscript.

\section{Ethics approval and consent to participate}

Not applicable.

\section{Consent for publication}

Not applicable.

\section{Competing interests}

Not applicable.

\section{Author details}

${ }^{1}$ Department of Hepatobiliary Surgery, First Affiliated Hospital, Wenzhou Medical University, Wenzhou, China. ${ }^{2}$ Department of Neurosurgery, First Affiliated Hospital, Wenzhou Medical University, Wenzhou, China. ${ }^{3}$ Department of Neurosurgery, Xinhua Hospital Affiliated to Shanghai Jiaotong University School of Medicine, Shanghai 200092, China. ${ }^{4}$ Department of Radiation Oncology, First Affiliated Hospital, Wenzhou Medical University, No. 2 Fuxue Lane, Wenzhou 325000, People's Republic of China.

Received: 10 July 2020 Accepted: 21 October 2020

Published online: 31 October 2020

\section{References}

1. Miller KD, Nogueira L, Mariotto AB, Rowland JH, Yabroff KR, Alfano CM, Jemal A, Kramer JL, Siegel RL. Cancer treatment and survivorship statistics, 2019. CA Cancer J Clin. 2019;69:363-85.

2. Lenneman CG, Sawyer DB. Cardio-oncology: an update on cardiotoxicity of cancer-related treatment. Circ Res. 2016;118:1008-20.

3. Yeh ET, Chang HM. Oncocardiology-past, present, and future: a review. JAMA Cardiol. 2016;1:1066-72.

4. Antoniak S, Tatsumi K, Schmedes CM, Grover SP, Pawlinski R, Mackman N. Protease-activated receptor 1 activation enhances doxorubicin-induced cardiotoxicity. J Mol Cell Cardiol. 2018;122:80-7.

5. Zhu W, Reuter S, Field LJ. Targeted expression of cyclin D2 ameliorates late stage anthracycline cardiotoxicity. Cardiovasc Res. 2019;115:960-5.

6. Milano G, Biemmi V, Lazzarini E, Balbi C, Ciullo A, Bolis S, Ameri P, Di Silvestre D, Mauri P, Barile L, Vassalli G. Intravenous administration of cardiac progenitor cell-derived exosomes protects against doxorubicin/ trastuzumab-induced cardiac toxicity. Cardiovasc Res. 2020;116:383-92.

7. Dhingra R, Guberman M, Rabinovich-Nikitin I, Gerstein J, Margulets V, Gang H, Madden N, Thliveris J, Kirshenbaum LA. Impaired NF-kappaB signalling underlies cyclophilin D-mediated mitochondrial permeability transition pore opening in doxorubicin cardiomyopathy. Cardiovasc Res. 2019.

8. Din S, Konstandin MH, Johnson B, Emathinger J, Volkers M, Toko H, Collins B, Ormachea L, Samse K, Kubli DA, et al. Metabolic dysfunction consistent with premature aging results from deletion of Pim kinases. Circ Res. 2014;115:376-87.

9. Karantalis V, Hare JM. Use of mesenchymal stem cells for therapy of cardiac disease. Circ Res. 2015;116:1413-30.

10. Hare JM, DiFede DL, Rieger AC, Florea V, Landin AM, El-Khorazaty J, Khan A, Mushtaq M, Lowery MH, Byrnes JJ, et al. Randomized comparison of allogeneic versus autologous mesenchymal stem cells for nonischemic dilated cardiomyopathy: POSEIDON-DCM trial. J Am Coll Cardiol. 2017;69:526-37.

11. Liu W, Rong Y, Wang J, Zhou Z, Ge X, Ji C, Jiang D, Gong F, Li L, Chen J, et al. Exosome-shuttled miR-216a-5p from hypoxic preconditioned mesenchymal stem cells repair traumatic spinal cord injury by shifting microglial M1/M2 polarization. J Neuroinflamm. 2020;17:47.

12. Shen H, Cui G, Li Y, Ye W, Sun Y, Zhang Z, Li J, Xu G, Zeng X, Zhang Y, et al. Follistatin-like 1 protects mesenchymal stem cells from hypoxic damage and enhances their therapeutic efficacy in a mouse myocardial infarction model. Stem Cell Res Ther. 2019:10:17.
13. Wang X, Chen Y, Zhao Z, Meng Q, Yu Y, Sun J, Yang Z, Chen Y, Li J, Ma $T$, et al. Engineered exosomes with ischemic myocardium-targeting peptide for targeted therapy in myocardial infarction. J Am Heart Assoc. 2018;7:e008737.

14. Huang P, Wang L, Li Q, Tian X, Xu J, Xu J, Xiong Y, Chen G, Qian H, Jin C, et al. Atorvastatin enhances the therapeutic efficacy of mesenchymal stem cells-derived exosomes in acute myocardial infarction via upregulating long non-coding RNA H19. Cardiovasc Res. 2020;116:353-67.

15. Zhu J, Lu K, Zhang N, Zhao Y, Ma Q, Shen J, Lin Y, Xiang P, Tang Y, Hu X, et al. Myocardial reparative functions of exosomes from mesenchymal stem cells are enhanced by hypoxia treatment of the cells via transferring microRNA-210 in an nSMase2-dependent way. Artif Cells Nanomed Biotechnol. 2018;46:1659-70.

16. Xu X, Pang J, Chen Y, Bucala R, Zhang Y, Ren J. Macrophage migration inhibitory factor (MIF) deficiency exacerbates aging-induced cardiac remodeling and dysfunction despite improved inflammation: role of autophagy regulation. Sci Rep. 2016;6:22488.

17. Zhang Y, Zhu W, He H, Fan B, Deng R, Hong Y, Liang X, Zhao H, Li X, Zhang F. Macrophage migration inhibitory factor rejuvenates aged human mesenchymal stem cells and improves myocardial repair. Aging. 2019;11:12641-60.

18. Wang J, Tong C, Yan X, Yeung E, Gandavadi S, Hare AA, Du X, Chen Y, Xiong $\mathrm{H}$, Ma C, et al. Limiting cardiac ischemic injury by pharmacological augmentation of macrophage migration inhibitory factor-AMP-activated protein kinase signal transduction. Circulation. 2013;128:225-36.

19. Chen H, Xia W, Hou M. LnCRNA-NEAT1 from the competing endogenous RNA network promotes cardioprotective efficacy of mesenchymal stem cell-derived exosomes induced by macrophage migration inhibitory factor via the miR-142-3p/FOXO1 signaling pathway. Stem Cell Res Ther. 2020;11:31

20. Gezer U, Ozgur E, Cetinkaya M, Isin M, Dalay N. Long non-coding RNAs with low expression levels in cells are enriched in secreted exosomes. Cell Biol Int. 2014;38:1076-9.

21. Liu Y, Duan C, Liu W, Chen X, Wang Y, Liu X, Yue J, Yang J, Zhou X. Upregulation of let-7f-2-3p by long noncoding RNA NEAT1 inhibits XPO1-mediated HAX-1 nuclear export in both in vitro and in vivo rodent models of doxorubicin-induced cardiotoxicity. Arch Toxicol. 2019;93:3261-76.

22. Li DS, Ainiwaer JL, Sheyhiding I, Zhang Z, Zhang LW. Identification of key long non-coding RNAs as competing endogenous RNAs for miRNA-mRNA in lung adenocarcinoma. Eur Rev Med Pharmacol Sci. 2016;20:2285-95

23. Penolazzi L, Lambertini E, Bergamin LS, Roncada T, De Bonis P, Cavallo M, Piva R. MicroRNA-221 silencing attenuates the degenerated phenotype of intervertebral disc cells. Aging. 2018;10:2001-15.

24. Markopoulos GS, Roupakia E, Tokamani M, Vartholomatos G, Tzavaras T, Hatziapostolou M, Fackelmayer FO, Sandaltzopoulos R, Polytarchou C, Kolettas E. Senescence-associated microRNAs target cell cycle regulatory genes in normal human lung fibroblasts. Exp Gerontol. 2017;96:110-22.

25. Ouyang C, Zhang S, Xue C, Yu X, Xu H, Wang Z, Lu Y, Wu ZS. Precisionguided missile-Like DNA nanostructure containing warhead and guidance control for aptamer-based targeted drug delivery into cancer cells in vitro and in vivo. J Am Chem Soc. 2020;142:1265-77.

26. Han D, Wang Y, Wang Y, Dai X, Zhou T, Chen J, Tao B, Zhang J, Cao F. The tumor-suppressive human circular RNA CirclTCH sponges miR-330-5p to ameliorate doxorubicin-induced cardiotoxicity through upregulating SIRT6, survivin, and SERCA2a. Circ Res. 2020;127:e108-25.

27. Gao S, Song Q, Liu J, Zhang X, Ji X, Wang P. E2F1 mediates the downregulation of POLD1 in replicative senescence. Cell Mol Life Sci. 2019;76:2833-50.

28. Anderson R, Lagnado A, Maggiorani D, Walaszczyk A, Dookun E, Chapman J, Birch J, Salmonowicz H, Ogrodnik M, Jurk D, et al. Lengthindependent telomere damage drives post-mitotic cardiomyocyte senescence. Embo J. 2019;38:e100492.

29. Lin L, Du L. The role of secreted factors in stem cells-mediated immune regulation. Cell Immunol. 2018;326:24-32.

30. Schorey JS, Harding CV. Extracellular vesicles and infectious diseases: new complexity to an old story. J Clin Invest. 2016;126:1181-9.

31. Aix E, Gallinat A, Flores I. Telomeres and telomerase in heart regeneration. Differentiation. 2018;100:26-30. 
32. Singla DK, Johnson TA, Tavakoli Dargani Z. Exosome treatment enhances anti-inflammatory M2 macrophages and reduces inflammation-induced pyroptosis in doxorubicin-induced cardiomyopathy. Cells. 2019;8:1224.

33. Lozano-Vidal N, Bink DI, Boon RA. Long noncoding RNA in cardiac aging and disease. J Mol Cell Biol. 2019;11:860-7.

34. Wang Y, Hu SB, Wang MR, Yao RW, Wu D, Yang L, Chen LL. Genomewide screening of NEAT1 regulators reveals cross-regulation between paraspeckles and mitochondria. Nat Cell Biol. 2018;20:1145-58.

35. Yamazaki T, Souquere S, Chujo T, Kobelke S, Chong YS, Fox AH, Bond CS, Nakagawa S, Pierron G, Hirose T. Functional domains of neat1 architectural IncRNA induce paraspeckle assembly through phase separation. Mol Cell. 2018;70(1038-1053):e1037.

36. Slade L, Biswas D, Ihionu F, El Hiani Y, Kienesberger PC, Pulinilkunnil T. A lysosome independent role for TFEB in activating DNA repair and inhibiting apoptosis in breast cancer cells. Biochem J. 2020;477:137-60.

37. Guo R, Ye X, Yang J, Zhou Z, Tian C, Wang H, Wang H, Fu H, Liu C, Zeng M, et al. Feeders facilitate telomere maintenance and chromosomal stability of embryonic stem cells. Nat Commun. 2018;9:2620.

38. Lin P, Wen DY, Li Q, He Y, Yang H, Chen G. Genome-Wide analysis of prognostic IncRNAs, miRNAs, and mRNAs forming a competing endogenous RNA network in hepatocellular carcinoma. Cell Physiol Biochem. 2018;48:1953-67.

39. Schulz J, Takousis P, Wohlers I, Itua IOG, Dobricic V, Rucker G, Binder H, Middleton L, loannidis JPA, Perneczky R, et al. Meta-analyses identify differentially expressed micrornas in Parkinson's disease. Ann Neurol. 2019;85:835-51.

40. Binas S, Knyrim M, Hupfeld J, Kloeckner U, Rabe S, Mildenberger S, Quarch K, Stratz N, Misiak D, Gekle M, et al. miR-221 and -222 target CACNA1C and KCNJ5 leading to altered cardiac ion channel expression and current density. Cell Mol Life Sci. 2019.

41. Shirakabe A, Ikeda Y, Sciarretta S, Zablocki DK, Sadoshima J. Aging and autophagy in the heart. Circ Res. 2016;118:1563-76.

42. Bonkowski MS, Sinclair DA. Slowing ageing by design: the rise of NAD(+) and sirtuin-activating compounds. Nat Rev Mol Cell Biol. 2016;17:679-90.

43. Shimizu K, Quillinan N, Orfila JE, Herson PS. Sirtuin-2 mediates male specific neuronal injury following experimental cardiac arrest through activation of TRPM2 ion channels. Exp Neurol. 2016;275(Pt 1):78-83.

44. Sarikhani M, Maity S, Mishra S, Jain A, Tamta AK, Ravi V, Kondapalli MS, Desingu PA, Khan D, Kumar S, et al. SIRT2 deacetylase represses NFAT transcription factor to maintain cardiac homeostasis. J Biol Chem. 2018;293:5281-94.

45. Kim HS, Vassilopoulos A, Wang RH, Lahusen T, Xiao Z, Xu X, Li C, Veenstra TD, Li B, Yu H, et al. SIRT2 maintains genome integrity and suppresses tumorigenesis through regulating APC/C activity. Cancer Cell. 2011;20:487-99.
46. Tang X, Chen XF, Wang NY, Wang XM, Liang ST, Zheng W, Lu YB, Zhao X, Hao DL, Zhang ZQ, et al. SIRT2 acts as a cardioprotective deacetylase in pathological cardiac hypertrophy. Circulation. 2017;136:2051-67.

47. Liu D, Ma Z, Di S, Yang Y, Yang J, Xu L, Reiter RJ, Qiao S, Yuan J. AMPK PGC1alpha activation by melatonin attenuates acute doxorubicin cardiotoxicity via alleviating mitochondrial oxidative damage and apoptosis. Free Radic Biol Med. 2018;129:59-72.

48. Xia W, Zhang F, Xie C, Jiang M, Hou M. Macrophage migration inhibitory factor confers resistance to senescence through CD74-dependent AMPK-FOXO3a signaling in mesenchymal stem cells. Stem Cell Res Ther. 2015;6:82.

49. Zhuang L, Xia W, Hou M. Coculturing with hypoxia preconditioned mesenchymal stem cells as a new strategy for the prevention of irradiationinduced fibroblasttomyofibroblast transition. Oncol Rep. 2019;42:1781-92.

50. Hu Y, Xia W, Hou M. Macrophage migration inhibitory factor serves a pivotal role in the regulation of radiation-induced cardiac senescencethrough rebalancing the microRNA-34a/sirtuin 1 signaling pathway. Int J Mol Med. 2018;42:2849-58.

51. Raso A, Dirkx E, Philippen LE, Fernandez-Celis A, De Majo F, Sampaio-Pinto V, Sansonetti M, Juni R, El Azzouzi H, Calore M, et al. Therapeutic delivery of miR-148a suppresses ventricular dilation in heart failure. Mol Ther. 2019;27:584-99.

52. Xia W, Zhuang L, Deng X, Hou M. Long noncoding RNAp21 modulates cellular senescence via the Wnt/betacatenin signaling pathway in mesenchymal stem cells. Mol Med Rep. 2017;16:7039-47.

53. Crepin T, Carron C, Roubiou C, Gaugler B, Gaiffe E, Simula-Faivre D, Ferrand C, Tiberghien P, Chalopin JM, Moulin B, et al. ATG-induced accelerated immune senescence: clinical implications in renal transplant recipients. Am J Transplant. 2015;15:1028-38.

54. Xie Z, Xia W, Hou M. Long intergenic noncoding RNAp21 mediates cardiac senescence via the Wnt/betacatenin signaling pathway in doxorubicin-induced cardiotoxicity. Mol Med Rep. 2018;17:2695-704.

55. Wang K, Long B, Zhou LY, Liu F, Zhou QY, Liu CY, Fan YY, Li PF. CARL IncRNA inhibits anoxia-induced mitochondrial fission and apoptosis in cardiomyocytes by impairing miR-539-dependent PHB2 downregulation. Nat Commun. 2014;5:3596.

56. Yang H, Liu P, Zhang J, Peng X, Lu Z, Yu S, Meng Y, Tong WM, Chen J. Long noncoding RNA MIR31HG exhibits oncogenic property in pancreatic ductal adenocarcinoma and is negatively regulated by miR-193b. Oncogene. 2016;35:3647-57.

\section{Publisher's Note}

Springer Nature remains neutral with regard to jurisdictional claims in published maps and institutional affiliations.
Ready to submit your research? Choose BMC and benefit from:

- fast, convenient online submission

- thorough peer review by experienced researchers in your field

- rapid publication on acceptance

- support for research data, including large and complex data types

- gold Open Access which fosters wider collaboration and increased citations

- maximum visibility for your research: over 100M website views per year

At BMC, research is always in progress.

Learn more biomedcentral.com/submissions 